\title{
REAL-TIME NUCLEAR POWER PLANT MONITORING WITH ADAPTIVELY TRAINED NEURAL NETWORK
}

\author{
K.Nabeshima, E. Türkcan, Ö. Ciftcioglu \\ Netherlands Energy Research Foundation ECN \\ P.O.Box 1 NL-1755 ZG,Petten, The Netherlands
}

\section{EXTENDED SUMMARY}

Real-Time nuclear power plant monitoring by feedforward neural network is described. For the training, standard backpropagation algorithm is used for an auto-associative network structure having 12 inputs/outputs. After initial training of the network, the real-time process signals are introduced to the network as input and plant status is monitored through the network's response at the output. At the same time the training of the network is performed in adaptive form so that the sensitivity of the network's failure detection sensitivity is enhanced in the course of the operation.The real-time monitoring system considered is primarily for the Borssele nuclear power plant (NPP) from which signals are available on-line with a sophisticated data acquisition system [1]. The neural network uses a three-layered feedforward structure with 7 nodes in the hidden layer. Standard backpropagation algorithm with sigmoidal nonlinearity is used for training and adaptive leaming. All input and output data are so normalized that the range extends from 0.1 to 0.9 . The program is coded in FORTRAN and executed at VAX-4200. For initial training 1850 patterns covering start-up, steady-state and shut-down are used, so that the wide-range operation of the plant is considered. After the initial learning, real-time monitoring and adaptive leaming starts to progress. The fault severity level $\left(\varepsilon_{i}\right)$ that is, measured and estimated signals difference normalized by related range, is taken to be 0.1 . The schematic block diagram of the monitoring system is shown in Fig. 1 where $\varepsilon_{\max }$ is the error bound used during the training as well as in real time. To illustriate the training and real-time monitoring system's performance, the results obtained from a process signal is given in Fig.2. The detailed description of this study is presented elsewhere [2].

The study demonstrates that a complex and dynamic system like a NPP can successfully be modelled by ANN, by the help of the measurement information only. Such a computational model can be used for monitoring of the system having several important advantages compared to conventional applied monitoring. For instance, the model comprises nonlinear dynamics which is approximated to linear system dynamics in most physical modeling applications due to the complexity of the problem.

\section{REFERENCES}

[1] Türkcan E.,Quaadvliet W.H.J.,Peeters T.T.J.M., Verhoef J.P.: "Operational Experiences on the Borssele NPP using Computer Based Surveillance and Diagnostics System On-Line" ECN-RX--91-057, The Netherlands, (June 1991).

[2] Nabeshima, K., Türkcan E., Ciftcioglu, Ö.: "Real-Time Nuclear Power Plant Monitoring with Adaptively Trained Neural Network", ECN-RX--93-146, The Netherlands (1993).
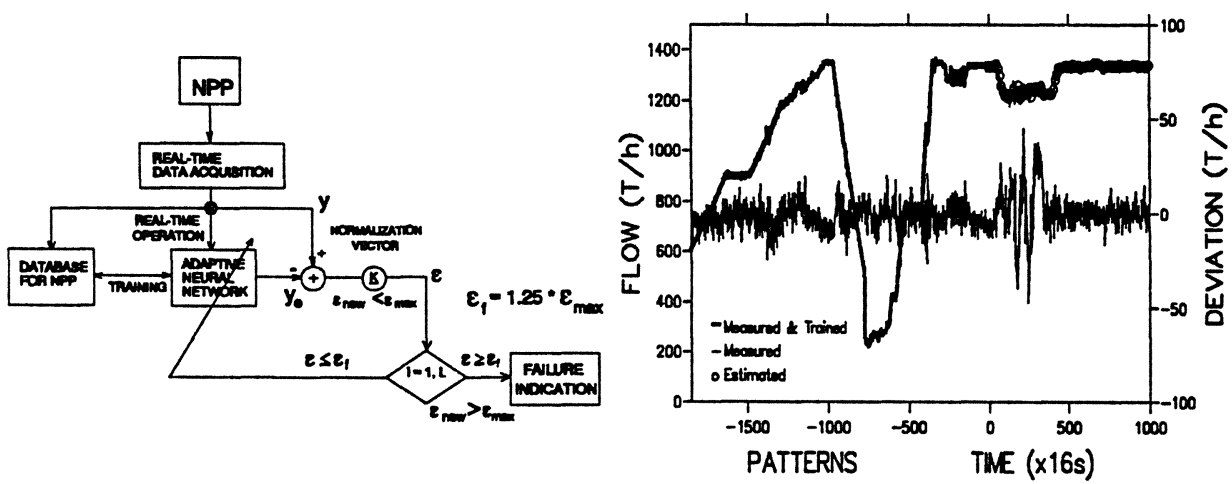

Fig.1. Block diagram of the monitoring system. Fig.2. Training and real-time estimation. 